\title{
VIAJE Y VOCACIÓN POÉTICA. LA POESÍA TEMPRANA DE DIANA BELLESSI, ENTRE SENTIDOS Y OTREDAD ${ }^{1}$
}

\author{
Travel and Poetic Vocation. Diana Bellessi's Early Poetry
}

Between Senses and Otherness

$51-63$

Martina Bortignon*

Resumen:

En una perspectiva que ve el viaje como momento de iniciación a la vida y al arte en el que el cuerpo y sus sentidos juegan un papel central, propongo leer las dos primeras obras de la poeta argentina Diana Bellessi - Buena travesía, buena ventura pequeña Uli (1974) y Crucero Ecuatorial (1981) - como búsqueda y encuentro con su propia vocación poética, gracias a la cercanía física a la gente que su viaje panamericano de seis años le permitió. Su respuesta a la apelación moral que le viene del otro será evaluada a la luz de los escritos teóricos de Bauman, Ricœur, Blanchot, y del aspecto retórico de los poemas mismos. En particular, en Buena travesía, buena ventura pequeña Uli el otro se manifiesta como voz, respiración, ritmo, con interesantes consecuencias en el tratamiento estilístico del texto. Por el contrario, en Crucero Ecuatorial prevalece una visualidad más calmada, más segura de sí misma: la "justa distancia" entre vocación poética y solidaridad humana ha sido conquistada.

Palabras clave: Diana Bellessi, Viaje, Iniciación, Poesía, Otro, Sentidos.

Abstract

On a perspective that considers travel as an initiation to life and art in which the body and its senses play a central role, I propose an interpretation of the first two works by the Argentinian poet Diana Bellessi - Buena travesía, buena ventura pequeña Uli (1974) and Crucero Ecuatorial (1981) - as the expression of the search and finding of her own poetic vocation, thanks to the physical closeness to people that she was able to experience in her sixyear-long trip through the two Americas. Her answer to the moral appeal proceeding from the other will be studied in light of the theoretical works by Bauman, Ricoeur, Blanchot, and the rhetorical feature of the same poems. In particular, in Buena travesía, buena ventura pequeña $U l i$, the other is manifested as a voice, breathing, rhythm, with interesting results in the stylistic treatment of the text. On the contrary, Crucero Ecuatorial reveals a calmer and more selfconfident position. The "right distance" between poetic vocation and solidarity has been attained.

Key words: Diana Bellessi, Travel, Initiation, Poetry, Other, Senses.

\footnotetext{
${ }^{1}$ Artículo desarrollado en el marco del proyecto de investigación CONICYT Fondecyt Postdoc $\mathrm{N}^{\circ} 3140423$ del cual soy investigadora responsable.
} 
Lástima la lucha no es sólo con vos Uli mochila anaranjada montada a su espalda como árbol raro

cuya raíz se inicia en ambos pies caminando.

Diana Bellessi, Buena travesía, buena ventura pequeña Uli

\section{EL VIAJE COMO INICIACIÓN}

Jean-Luc Nancy, al revisar el desarrollo de la relación ser humano-mundo en su ensayo Corpus, anuncia que, después del mundo como cosmos - reflejo del orden divino - y res extensa - cartografia de los espacios a conquistar - , ha llegado la etapa del mundus corpus, esto es, el mundo como "poblamiento proliferante de los lugares (del) cuerpo" (33). El habitar y el recorrer el espacio mundano se resolverían ahora - o por lo menos este parece ser el auspicio del filósofo- en el con-tacto entre cuerpos singulares que con-viven y se confrontan desde sus individualidades plurales. En particular, en el momento en que los sujetos se abren a la experiencia de la otredad, por ejemplo en un viaje, la exploración se dará en términos de una superposición y coincidencia carnales entre lugares y personas, entre otredad geográfica y otredad humana:

Los países: ni territorios, ni dominios, ni suelos, estas extensiones que se recorren sin jamás reunirlas en una sinopsis, ni subsumirlas bajo un concepto. Los países siempre extranjeros, y el extranjero en tanto que país, comarcas, parajes, pasajes, travesías, vistas que se abren, relieves inesperados, caminos que conducen a alguna parte, a ninguna parte, partida, regresos (Nancy, 44-45).

Una visión teórica como esta, que realza la vertiente corporal de la apertura del sujeto al mundo y la vuelve un elemento de compromiso radical con la existencia, permite mantener la problemática del viaje, como es planteada en la reflexión contemporánea, en una línea de continuidad con la tradición de los peregrinajes medievales, de le grand tour moderno o del vagabundeo beatnik; dicho de otro modo, testimonia el hecho de que el viaje puede llegar a ser una instancia de transformación íntima e integral del individuo, una suerte de iniciación. En la línea del tiempo el viaje representa, efectivamente, un corte, un síncope, un potencial de extrañamiento que se condensa en la paradoja del regreso, en aquellos mínimos actos de desencuentro con la realidad de pertenencia que evidencian la brecha y el cambio, a veces insalvables e irrecuperables, que se han instalado en la psiquis y en el cuerpo de una persona. El acto de desplazarse en el espacio, de experimentar costumbres y sabores diferentes, o de sumirse en la corriente de un idioma desconocido, puede ser leído como camino de autoconocimiento mediante de la otredad sobre el cual la garganta se cierra, con pudor. No es casual que, a menudo, lo crucial en la experiencia de viaje - a pesar y en contra de la socialización en tiempo real que las herramientas digitales han puesto a disposición del usuario en la hipermodernidad- resulte incomunicable, exactamente como el núcleo ominoso de los ritos de iniciación. Frente a las clásicas preguntas puestas al regreso, la experiencia del viaje se descubre ya integrada a los huesos, los muslos, las retinas: dificilmente verbalizable. El sabor del vértigo arriba de 
los ríos profundos, el aire espeso de contaminación de las capitales, los remolinos en el desierto al mediodía, no se pueden describir, porque ya están inscritos en el cuerpo, en un idioma mudo y remoto.

Es en esta doble perspectiva de un viaje como corporeidad y como iniciación que me interesa emprender la lectura de dos poemarios - Buena travesía, buena ventura pequeña Uli (escrito en 1974 y publicado en 1991) y Crucero Ecuatorial (1981) - que la poeta argentina Diana Bellessi ha dedicado al viaje más largo y crucial de su vida. En la primera mitad de los años 70, la poeta recorrió mochileando la "patria grande" americana, hasta llegar a Estados Unidos. En una entrevista, la autora declara:

El viaje más largo duró del 69 al 75, después de haber hecho otros más cortos. Este fue como la escuela primaria para mí. Salí hacia Chile con una mochila, un sueldo de maestra y unas intenciones no muy definidas. Cuando llegué decidí dar una vuelta por todo el continente y empecé a vagabundear por distintos países. Hice de todo: trabajé en fábricas, en imprentas, fui contrabandista, pedí limosna en la calle. También hice periodismo y conocí a muchos intelectuales serios, a muchos poetas [...] (Ojeda, en línea).

En las dos obras consideradas, la poesía se entrelaza y se funde con la bitácora de viaje para dar cuenta de dos aspectos: el viaje se connota como un momento de formación que le permite a la sujeto transitar a la edad adulta; por otra parte, la experiencia del viaje funciona en tanto búsqueda de la vocación artística e iniciación a la palabra poética. Ambas vertientes confluyen en el común denominador del dato corpóreo, sensible. La confrontación existencial con la otredad se da por medio de un radicalismo que pone en juego a la sujeto con su cuerpo individual frente a otros cuerpos individuales, resultando, en un caso, en la aniquilación de las fronteras corpóreas y enunciativas y, en el otro, en la adquisición de una identidad reconocible y estable. La aventura poética, que avanza paralelamente, traduce el desafío vivencial en los términos de una predominancia, en la retórica del poema, de un sentido perceptivo sobre los demás. El oído, en el caso de Buena travesía, buena ventura pequeña Uli y la vista en Crucero Ecuatorial son los canales mediante los que la sujeto responde tanto a la convocación a la responsabilidad moral por parte de la otredad, como al llamado más íntimo y personal a abrazar su vocación artística.

\section{BUENA TRAVESÍA, BUENA VENTURA PEQUEÑA ULI: EL OTRO COMO VOZ Y OBSESIÓN}

Buena travesía, buena ventura pequeña Uli, escrito en 1974, fue sin embargo publicado casi veinte años más tarde, en 1991, cuando Diana Bellessi ya se había convertido en una de las voces más interesantes en el panorama de la poesía de esos años. Como recuerda la poeta en una entrevista, Buena travesía... fue "(...) un libro escrito on the road" (Vaccarini y Docampo, en línea), paralelamente al desarrollarse el viaje. Caracterizado por una fuerte vocación experimental, entre el flujo de 


\section{Martina Bortignon}

conciencia beatnik y el imaginario pizarnikiano, el libro está conformado por textos en prosa poética en los que el ritmo está pautado por recursos tipográficos — como los espacios en blanco o la barra- insertados sin un criterio sintáctico, y por una cuidadosa distribución de los acentos, gracias a la cual se produce una aceleración cuando prevalecen las palabras agudas, y un ritmo casi hipnótico con las llanas. Hay que añadir también la presencia del anacoluto y de los truncamientos sintácticos, que no solamente responden a la voluntad de intersectar la linealidad de la frase rítmica con imprevisibles síncopes, o bien, de adherirse a la espontaneidad del lenguaje coloquial, con sus típicos false starts y cambios de estructura gramatical sobre la marcha, sino que de manera consciente intenta socavar desde adentro la sintaxis de la frase, en busca de una apertura a la ambigüedad de la identidad de los sujetos aludidos y a la multiplicidad de los puntos de vista. De hecho, en Buena travesía, buena ventura pequeña Uli, la instancia escritural ${ }^{2}$ fragmenta la locución y la divide entre una serie de voces mezcladas con el white noise de un mundo bullente y desmedido; en otras palabras, el texto se resiste a entregarle al lector un yo poético claramente definible. De una forma similar, las alusiones al viaje, representadas por las denominaciones de los lugares, de los encuentros con autóctonos u otros viajeros, $y$, sobre todo, por el choque con la realidad de opresión sufrida por los más débiles (presos políticos, mujeres, indigentes, campesinos, indígenas) en los países visitados, aparecen según un ritmo intermitente, por medio de escuetas alusiones, con el efecto de que se va creando un panorama proteico, agujereado por múltiples entradas y salidas, en lugar del clásico mapa cruzado por un itinerario que pasa ordenadamente de una etapa a la sucesiva. Véase como ejemplo el siguiente fragmento, donde las ciudades recorridas (San Francisco, Nueva York, Oakland), las músicas escuchadas en las calles o los locales (un blues improvisado, un tema jazz de Chick Corea, una canción de Janis Joplin) y las personas encontradas (los homeless, los lisiados de la guerra en Vietnam, los drogadictos) se comprimen en un aleph que todo lo contiene, en un vértigo que corta el aliento. La sensación de mareo se genera también a partir de las ya mencionadas técnicas retóricas de cambios improvisos de sujeto gramatical y de enumeración por enunciados relativamente largos, que desorientan en la atribución de una fisonomía coherente a los personajes convocados y exaspera la dicción y el ritmo en una lectura acelerada e hipnótica a la vez.

Cuando su amiga negra salida de una estampa de Louisiana en los 30 sobre el malecón de San Francisco canta sus blues, cuando la figura de aquel ojos afiebrados que el viento evade/bajo su saco de pieles se pierde en el horizonte

\footnotetext{
${ }^{2}$ Llamo 'instancia escritural' o 'conciencia escritural' a la entidad que organiza el material poético, elige estilo y retórica, dirige el juego de las voces: en una palabra, la responsable de la enunciación poética. El poema puede ser considerado el epifenómeno de su voz. Difiere del concepto de autor, que alude en cambio a una dimensión exterior al enunciado poético. Me permito reenviar a mi artículo "El sujeto enunciativo en poesía. Propuesta de un modelo de estudio", Gramma, Universidad del Salvador, Buenos Aires, 2014 (en imprenta) para una teorización de la enunciación en poesía.
} 
de la Market street, cuando Chick Corea detiene el piano en dos notas y dentro de ellas extiende, desolado a Nueva York, cuando algún memorial hace temblar los estéreos con tus gritos mi Janis, cuando se acuestan sobre la calle entre papeles y latas de cerveza y toda la ciudad los patea, cuando duerme, cuando nos despertamos con tantas grietas en los labios que en ellas podrían dibujarse las más fastuosas miniaturas de nuestro tiempo, cuando lo besa en el fondo del autobús que atraviesa el puente de la Bahía de Oakland y apoya su mano sobre el vacío de tu pierna amputada en el Vietnam, cuando cortan hojas tiernas mojadas por la lluvia y las apoyan sobre sus ojos, a la hora que el que pudo tomó su droga y el que no camina o dormita en las adyacencias de los campus en la Mission en los alrededores del Greyhound o toca una armónica diminuta para tristeza de las rosas del Rose Garden (70).

Con esta fragmentación, disonancia y aceleración como plataforma expresiva, el poemario se tambalea sobre la disyuntiva entre el llamado al activismo político y la atracción por la actividad artística. Es este el nudo en que se juega el valor del viaje como recorrido de iniciación. Considerado en su totalidad, el libro describe una evolución que empieza en un tiempo que se podría intuir como prenatal, luego pasa por la infancia, la adolescencia y finalmente la salida al mundo real, que determina un impacto traumático con la violencia perpetrada por un ser humano sobre otro, para llegar a una conciliación de la autoconsciencia poética con las múltiples voces que la acompañan y la pueblan ${ }^{3}$. Los diferentes aspectos de esta lucha interior entre el principio de realidad (el llamado a involucrarse con el sufrimiento de los demás) y el del placer (el vicio culposo de amar el lenguaje) son personificados por una serie de figuras que, como se puede intuir, representan las diferentes facetas de un sujeto poético disperso, constitutivamente imposibilitado - pero también conscientemente reacio- a una recomposición, que la locutora ${ }^{4}$ del poema interpela directamente en su afán por progresar en el camino de su autoconocimiento.

Uli — personificación de la poesía - es una especie de duende cruel e inocente que juega con la ensoñación y la ilusión y por medio de cuyas piruetas se conectan y se enfrentan las dos caras de una misma moneda: "Por la uña de los torturados podés entrar a una guitarra. Por los hambrientos de la Tierra al fresco más glorioso que dio el Renacimiento. Por los obreros de la sociedad norteamericana y su electrónico computador al libro más terrible de poemas" (66). Sin embargo, Uli no parece darse cuenta, perdida como está en su mundo abstraído, de la gravedad de ciertos sucesos; de hecho, como afirma la locutora, las voces de los desposeídos "son las voces que

\footnotetext{
${ }^{3}$ La lectura en el sentido de una iniciación y de una biografía de la voz poética desde su nacimiento, crecimiento hasta la madurez es refrendada por términos específicos en el texto: "A la hora de la iniciación en la desesperanza, empieza su cuento", “de aquí partió la pequeña Uli”, "En su crecimiento", "crecía Uli”, para limitarse solamente al primer fragmento (Bellessi, 9).

${ }^{4} \mathrm{Si}$ la instancia escritural es la responsable del preliminar acto de la enunciación en que se origina el poema, el locutor o locutora es la voz que aparece a nivel de la diégesis o enunciado. En el caso de que esta voz tome cuerpo en una figura al interior del poema, se habla también de actor del enunciado o personaje.
} 


\section{Martina Bortignon}

Uli nunca puede escuchar" (62). Otro personaje, Nadia, en el que no es dificil leer un anagrama de Diana, el nombre de la autora, representa un espíritu errante, viajero: "¿Por qué Nadia atravesaba el planeta / atravesaba los veranos como si no fuera a detenerse ni para el Año de Ñaupa?" (61). Uli y Nadia velan el nacimiento de la mujer D, otra alusión al nombre biográfico, condenada por la misma Uli "a la casa cruel del lenguaje" y a amar "los verbos en condicional y los adjetivos absolutos" (64): ella obviamente representa la autoconsciencia poética. Finalmente, más adelante en el poemario, aparece Una, o sea una entre las mujeres, figura en la cual se condensan las historias y las voces de las mujeres del mundo.

La instancia escritural crea, por lo tanto, un teatro de personificaciones con las cuales la locutora — cuya identidad sigue siendo escurridiza- se enfrenta dialógicamente en busca de una resolución a su dilema existencial: seguir "todas las hermosas revolucionarias del mundo las cuales, al convertirse en una sola con el resto de la gente no dejaron espacio para Uli" (57) y acabaron demostrando su inexistencia, o rendirse ante la fascinación del arte, esto es, lo que queda más allá de la inmediatez del ser, pero que al ser alude: "[...] caer en espiral y vernos en constantes apariciones de lo que no es Uli pero Uli manifiesta" (72). Al final, la conciliación con el llamado a una forma de activismo político —o sea, de respuesta a la convocación por parte de $e l$ otro ${ }^{5}$ - que pase por medio del lenguaje y de la creación artística, se produce al colocar el lugar de enunciación junto con las voces de las mujeres del mundo. No es accidente que el poemario se cierre con una serie de poemas anónimos o firmados con los nombres de otras mujeres y con la imagen del cadáver de una guerrillera que, paradójicamente, en su olor a putrefacción permite que prolifere la energía revolucionaria femenina.

Como resalta a la vista, este recorrido poético-ficcional utiliza el locus literario del viaje de iniciación como metáfora de la iniciación a la poesía, en donde la presencia de el otro es un elemento irrenunciable. Me interesa ahora vincular la escritura de Diana Bellessi con la ética de la responsabilidad hacia el otro postulada por Emmanuel Lévinas, tal como ha sido retomada por Paul Ricœur. Este último, en unos estudios de su ensayo Sí mismo como otro, procura abordar la propuesta de Emmanuel Lévinas desde el eje de la enunciación. El otro se manifestaría, antes que nada, como una voz: "Cuando el rostro del otro se alza frente a mí, por encima de mí, no es un aparecer que yo pueda incluir en el recinto de mis representaciones; es cierto que el otro aparece, que su rostro lo muestra, pero su rostro no es un espectáculo, es una voz" (Ricœur, 373); una voz que, en su proximidad, se hace urgente, apremiante, obsesiva. Me parece que en Buena travesía... la presencia de el otro se evidencia

\footnotetext{
${ }^{5}$ La separación entre preposición y artículo permite evitar la escritura de "otro" en cursiva o con inicial mayúscula, soluciones que conllevan el riesgo de absolutizar y reificar el ser humano que el sujeto percibe como otro respecto de sí. La solución elegida permite distinguir entre "otro" sustantivo (cargado de significado filosófico) y "otro" adjetivo (elemento gramatical del discurso). No se ha hecho lo mismo con la preposición "a" en composicón con "el", por sonar demasiado fuerte la separación.
} 
justamente como sonido, ruido, ritmo, respiración, y, gracias a las estrategias retóricas destacadas más arriba, se infiltra profundamente en el cuerpo mismo del texto. Es la sonoridad misma del poemario la que contiene y expone al otro. El llamado obsesivo de este último y la insistencia de su voz exigiendo una respuesta moral impiden que la sujeto asuma plenamente su rol poético. Se puede comprobar la intensidad de la lucha interior de la instancia poética ${ }^{6}$ precisamente en el hecho de que la voz del poema queda adherida con las voces que la rodean y la intersectan. Por citar un ejemplo, en el siguiente fragmento este conflicto se manifiesta en la asociación entre la problemática de la voz con el relato metafórico de la migración de un joven ave, lo que mantiene la reflexión dentro del marco temático del viaje.

Mi Nona me escribió una carta preguntándome qué hago en estas lejuras y yo le cuento el sueño de un pato salvaje que perdió su bandada mientras andaba emigrando. De nosotras Uli, vos sabés que están las que murieron en su ley las que pasaron a mercenarias y las que creciendo trabajan lindo por lo alto y por lo bajo para hacer la Revolución ¿Qué me pasó que quedé atrás Uli? ¿En qué alambrada se engancharon las plumas y mientras graznaba por desasirlas empezó tu vocecita a tararear baladas del Día por encontrar? En el bagazo de las grandes ciudades donde casi no puedo escuchar una voz humana la tuya Uli me las dice en pasado, sobre todo los gritos cuando hubo levantamientos y masacres sobre todo las del Sur, tango furioso de esos que pocas veces se han escrito por pasar tanto tiempo llamando a Uli en los cafés. Tango que camine las Villas Miserias pasillos de las fábricas las cárceles los colectivos a la salida del trabajo mataderos las oficinas un verano a las 3 de la tarde y la cara de todos los que rodaron bajo cascos de la montada gases lacrimógenos y pistolas Un tango Uli que no podés escribirlo vos ni yo perdida en estas lejuras pero quizás mañana, cuando crezcan las plumas últimas, esas que se mueren con una quizás mañana Uli, al menos consiga cantarlo porque ¿quién te dijo a vos que yo era la que andás buscando? (78-79)

La locutora se presenta como el "pato salvaje" que se desprende de su bandada (el grupo de las demás mujeres, más directamente comprometidas con la causa política de la Revolución) y queda atrapado en una alambrada: su graznido se topa con el tema repetitivo musitado por el espíritu de la poesía, que en la prosecución de su viaje se vuelve el mediador de todos los demás gritos de la humanidad sufriente y rebelde. Las plumas de las alas, las mismas que le permiten al pato volar, podrían trasformarse, en el momento en que despunten, en medios de expresión, en plumas para escribir un tango. Frente a esta tarea, sin embargo, la locutora se siente inadecuada. Queda patente como su voz no logra independizarse ni de los gritos de los demás seres humanos ni de la letanía hipnótica del espíritu de la poesía; no logra, en otras palabras, cavar una distancia que le permita recrearlas a nivel artístico, sino que solo auspicia poder cantar tal cual (esto es, reproducir, repetir, reverberar) el tango ya formulado por las voces de los

\footnotetext{
${ }^{6}$ Entiendo por "instancia poética" o "conciencia autoral" la actitud que asume la instancia escritural cuando pronuncia las reflexiones metatextuales y la percepción de su propia evolución artística.
} 


\section{Martina Bortignon}

demás en el ruido ensordecedor de las ciudades. Su voz es una voz poseída, habitada por otras voces.

La imposibilidad de desprenderse de la presencia material y sonora de el otro colectivo conlleva una importante consecuencia a nivel moral. Como destaca Bauman en su lectura de Lévinas, "[...] el impulso moral precede el habla. Tampoco requiere normas, es su propia norma, fija su norma conforme avanza, es un acto de creación continua. No conoce la culpa ni la inocencia; es la pureza de la ingenuidad" (127). La respuesta a la convocación por parte del otro se da antes de que se produzca el distanciamiento racional, pasaje necesario para llegar a la representación; antes de que la voz se distribuya ordenadamente en las sílabas y en las palabras, produciendo el habla. En Buena travesía... la réplica moral es flatus vocis - la voz como soplo de aire, aliento (Bologna)-, es tatuaje en las carnes mismas: "Después, viví a veces en un sueño y a veces fuera de él: en ambos grito" (Bellessi, 80); "Nadia chilló de tristeza al saber que estaba tatuada dentro de un dibujo tatuado en el corazón de Uli" (55). La opción de una vita activa en sentido político, si bien a menudo presentada - "¡Oei! ¡Oei!: si te vas Uli, dejo la poesía y me compro una escopeta" (75) - no es finalmente nunca llevada a cabo en el texto, justamente por los riesgos que conlleva a nivel de representación y consiguiente enmudecimiento del otro, quien de encontrado se volvería inventado, construido, finalmente cortado fuera del campo de escucha de la instancia escritural. De hecho, el conocimiento, como explica Bauman, conduce a la representación de el otro, indispensable para que se dé la responsabilidad: para hacerse cargo del "tú", para darle voz, el "yo" tiene que conocerlo, por lo tanto representárselo según sus propias categorías. Sin embargo, en ese punto el otro resulta mediado, irremediablemente traicionado en su ser, creado y no encontrado. El otro se vuelve mudo, mientras la responsabilidad y el cariño del sujeto se transforman en poder, autoridad, incluso opresión. Es así como, en este momento temprano del desarrollo de la voz poética, es el sonido áspero y agudo lo que prevalece, no la abstracción y racionalización en palabras y frases: el poema hace audible un eco, un reclamo, una apelación recíproca e íntima de entraña a entraña, una urgencia moral hacia el otro que rebasa lo verbal y lo verbalizable.

\section{CRUCERO ECUATORIAL: LA VISUALIDAD Y LA PROXIMIDAD}

El poemario Crucero Ecuatorial, publicado en Buenos Aires en 1981, si bien flirtea con el formato y la retórica del diario de viaje, por ejemplo mediante un estilo muy escueto y visual y de la titulación de los poemas con números romanos, como si fueran postes al borde de un camino, fue en realidad redactado retrospectivamente, cuando ya la poeta había regresado a Argentina. De hecho, como recuerda la poeta, "fue un libro hecho en una semana, pero no mientras estaba caminando sino en rememoración" (Vaccarini, en línea). Entre el acto enunciativo y los hechos relatados se inserta, por lo tanto, una brecha temporal, que se explicita por medio del uso del tiempo pretérito en los verbos y de marcadores deícticos como "aquel", "allá", entre 
otros. Sin embargo, el tiempo presente del acto de reordenamiento artístico y emocional de la experiencia emerge de forma discreta, aunque constante, como enlace para que se produzca el acontecimiento memorístico, por ejemplo por medio de imágenes-puente que permiten que un recuerdo vuelva a la mente. Como destaca también el crítico Javier Bello, es de central importancia para la comprensión del significado del poemario que la enunciación se dé desde la inmovilidad: sobre el viaje se reflexiona desde la detención, con un desapego que proporciona lucidez aunque la emoción siga siendo muy viva. En el poema programático de apertura, la locutora sugiere implícitamente el posicionamiento estratégico de su voz.

Algo de aquel fuego quema todavía.

La luz del sol móvil

sobre la copa de los árboles,

y mi corazón desbocado, de deseo.

Afuera, al alcance de mi mano

la fiesta.

Los tiempos verbales

amarrados, como helechos a una misma piedra. (117)

La imagen contenida en la última frase da cuenta de este acto de rememoración, ya que los tiempos verbales (los recuerdos) son reunidos en un manojo y dependen de un punto de vista que los sostiene con fuerza. En otro verso ("mi corazón desbocado, de deseo"), la locutora matiza su actitud hacia la materia a poetizar: una actitud apasionada. Estos dos elementos son determinantes para la interpretación de la obra porque reflejan la estrategia con que la poeta se ficcionaliza como personaje interno a las situaciones que va describiendo. Por una parte, se posiciona muy claramente en el espacio y en relación con los otros personajes: "Cerca del mercado / de Oaxaca, / sentada en el umbral / de la vereda/ veo pies caminando" (143) y, por la otra, se describe como guiada por una voracidad deseante que se parece al hambre - hambre de conocer realidades diferentes, de vivir experiencias intensas - . "Era tanta mi alegría, mi deseo / como el que vi en los ojos / de un camionero aindiado / que miraba las matracas / los juegos de artificio / mientras nos guardábamos de la lluvia / bajo un tinglado de chapa" (138).

El poema se constituye, por lo tanto, como espacio privilegiado para el encuentro entre la protagonista y el otro. Este último es invitado a ingresar en el poema verbalmente por medio de su voz, como en las escenas construidas alrededor de diálogos que alternan las formas del discurso directo e indirecto (el primero incluso diferenciado del texto del poema trámite cursiva), o bien visualmente mediante la evidencia icástica de su mismo cuerpo. Por ejemplo, la forma en que son retratados los campesinos ecuatorianos: "Hombres y mujeres en los campos, / con el palo de escarbar / y la cara rosadita vuelta / hacia el tren que pasaba" (133). En ambos casos, la perspectiva es focalmente definida y restringida, ya que la porción de mundo que se retrata en cada poema se mide basándose en la cadencia del paso de la viajera, 


\section{Martina Bortignon}

imitando, diríase, el formato de una fotografía. De hecho, Crucero Ecuatorial está conformado por textos que se señalan por su fuerte carga visual, realzada aún más por la sobriedad estilística y la tendencia a privilegiar el sintagma nominal por encima del verbal, lo que "bloquea" el movimiento, exactamente como en una imagen fotográfica.

Sencillez y claridad son las huellas digitales de una voz que se encarna en un cuerpo específico, el de una "pequeña vagabunda americana", como se autodefine la locutora en un poema, por medio de cuyos ojos desfilan las experiencias y los encuentros. Justamente gracias a esta perceptibilidad física y definida del yo poético, quien no dobla el equilibrio del texto a su favor, sino que hace sitio para que otros puedan emerger, se produce para el lector la posibilidad de identificarse con la protagonista y su sensibilidad. Como se puede ver, la éducation sentimentale de la joven protagonista a la poesía se ha producido gracias a la conquista de una equidistancia entre ella misma, las experiencias vividas y las personas con las que ha entrado en un contacto a lo largo del camino. La excepcional proximidad respecto de los demás que el viaje posibilita es el manantial en el que se abreva la conciencia poética para darle trayectoria a su inspiración ideológica. Un poema, en particular, hace el recuento de unos cuantos compañeros y de sus nombres y se cierra con un verso emblemático que da cuenta del proceso gradual con que se forma la subjetividad poética a partir de la otredad:

Nombres,

para citar algunos, me acuerdo de Pimentel, como un oscuro gladiador peruano convencido, violento, triunfal, comiendo conmigo un platito de mondongo

en los altos de un restaurant barato.

Después a la chica de aquella tarde de domingo que me paró en la esquina y dijo quería regalarme plata.

Su abrazo me calienta todavía $\mathrm{y}$ en realidad no necesito memoriarle nombre a su cara.

También me acuerdo de Rosendo, el zapatero, que perdí en un tren de Cuzco hacia Arequipa, y creía en las cosas simples como yo creí mañana.

Por último, al negrito Verástegui, con un cordero entre los brazos. Mano a mano, el poeta. (126) 
Además, el último poema de Crucero Ecuatorial, con clara intención metapoética, explicita el legado del largo viaje por tierras americanas en la imagen de una guitarra fabricada por un artesano de la calle con clavijero de madera y cuerdas de alambre, y se cierra con los siguientes versos: "Vuelvo a sacarte, con rasguido popular, / imperfecta, sensiblera, mi guitarra" (134). En otras palabras, la voz poética ha absorbido los matices de la sensibilidad popular y de su universo expresivo justamente gracias al hecho de que este viaje, más que con un recorrido por medio de paisajes y geografias, ha coincidido con una exploración de los rostros humanos del continente.

El necesario distanciamiento respecto de lo vivido, favorecido por la ya comentada posición enunciativa a posteriori, dimensiona la desbocada vocalidad que protagoniza Buena travesía, y la vuelve lúcida verbalización, más similar a la mirada que a la producción lingüística. Volviendo a leer las páginas que Bauman dedica a la relación moral con el otro, esta vez comentando a Blanchot, se puede comprobar cómo en Crucero ecuatorial se aplica la ética de la atención, de la espera, que permiten dejar un espaciamiento entre los sujetos, sin que el horror vacui inste a llenar las oquedades de la relación con una representación. Este intervalo equilibrado se llama "proximidad". Escribe Bauman: "[1]a proximidad no es una distancia unida —ni que exija ser unida - por un puente; no es un preámbulo a la identificación y a la fusión que podría, en la práctica, ser sólo un acto de tragar y absorber. La proximidad está satisfecha de ser lo que es: proximidad. Y está preparada para permanecer como tal: en un estado de atención permanente, pase lo que pase" (102). La proximidad, que se acerca pero a la vez mantiene la distancia con el objeto en la espera respetuosa, permite que se dé la palabra, sin que el discurso intente asir al otro. El llamado a la responsabilidad moral por parte de este último se hace ahora más claro; como ya en Lévinas, lo que aparece esta vez es el rostro, pero sin desencadenar un afán desordenado de compensación vocal-carnal por parte de la instancia escritural como en el poemario precedente. De hecho, en Crucero Ecuatorial la epifanía del rostro de la alteridad se traduce casi siempre en una meditación estética que denota la capacidad de transformar en arte el dato existencial, liberándolo de la carga más directa e ingenuamente revindicativa. En el poema "IX", por ejemplo, la presencia de una joven prostituta en un burdel de Lima es sutilmente sugerida por la metonimia de sus calzones, que se sobreponen justamente a la figura de una cara, la cara de el otro. El poema termina así:

Una tarde abrí la puerta

sobre un largo, angosto corredor,

y encontré colgando del picaporte

la bombachita raída

que alguna joven prostituta

abandonara.

La recuerdo,

vívidamente, como a una cara (125). 
Como se ve, la pacificada consciencia de la vocación artística permite una mediación entre subjetividades en la lucidez y limpidez de la mirada. Apelando al sentido de la vista, que permite una valoración más global y desapegada, Crucero ecuatorial condensa, así, el viaje de iniciación de la poeta con una galería de retratos y paisajes, como hitos en un camino en busca de la "justa distancia".

\section{HACIA LA “JUSTA DISTANCIA”}

Blanchot, en uno de los estudios que conforman El diálogo inconcluso, reflexiona sobre la diferencia entre mirar y hablar o escribir. Según él, el acto de ver supone una separación que se puede medir en la pausa que se crea entre el sujeto y el objeto. Se ve gracias a una privación, a una interrupción y un alejamiento, mientras que cuando las cosas se hacen demasiado presentes, o bien cuando el sujeto es demasiado presente a ellas, la visión es imposible. Por otra parte, escribir no necesariamente corresponde a enseñar la palabra como unidad significante: a menudo esta última se manifiesta como corte, crisis, desgarro (Blanchot, 1993). Una diferencia parecida, como he intentado demostrar a lo largo del presente escrito, media entre las dos obras poéticas, distintas pero complementarias, que Diana Bellessi compuso alrededor de la experiencia de iniciación del viaje. Por una parte, Buena travesía, buena ventura pequeña Uli, es testimonio de la maduración progresiva de una conciencia poética frente a los impulsos que guiarían al sujeto hacia otros modos de acción en respuesta al llamado del otro: al final del poemario - y del viaje metafórico y real - se perfila la posibilidad de una reconciliación con el don de la poesía, con su indirecta pero profunda capacidad de cambio en la realidad. La conciencia autoral, todavía en pleno desarrollo, a esta altura de su aventura artística escoge privilegiar un acercamiento casi carnal con el otro, lo que se traduce en una prosa poética jadeante, intensa, material: con todos los sentidos abiertos pero con los ojos cerrados. Por otra parte, está Crucero ecuatorial, balance retrospectivo y más meditado, conquista de una "justa distancia" entre la enunciación, las experiencias y las emociones del viaje que, aunque muy vivas en la memoria - "Algo de aquel fuego quema todavía" recita el primer verso del poema programático de apertura - se hacen ahora visibles desde una perspectiva que las estructura en un sentido global. La evidente vocación visual del poemario subraya esta intención de completud y orden. La conciencia poética ha por fin descubierto paz y razón de ser tanto en su vocación artística como frente a la apelación moral de un otro que, por fin, puede ser visualizado y acogido dentro la escritura y desde una justa distancia, como multiplicidad de otros autónomos.

\section{Universidad Adolfo Ibáñez/Pontificia Universidad Católica de Chile* Diagonal Las Torres 2640, Peñalolén, Santiago (Chile) martina.bortignon@uai.cl}


Viaje y vocación poética. La poesía temprana de Diana Bellessi

\section{OBRAS CITADAS}

Bauman, Zygmunt. Ética posmoderna. Buenos Aires: Siglo XXI, 2004.

Bellessi, Diana. Tener lo que se tiene. Poesía reunida. Buenos Aires: Adriana Hidalgo, 2009.

Bello, Javier. "Diana Bellessi: Inmóvil transparente. Crucero ecuatorial". Cyber Humanitatis 24 (2001), www.vendavalsur.com.ar (25/02/2012).

Blanchot, Maurice. El diálogo inconcluso. Caracas: Monte Ávila, 1993.

Bologna, Corrado. Flatus vocis. Metafisica e antropologia della voce. Bologna: Il mulino, 2000.

Nancy, Jean-Luc. Corpus. Madrid: Arena Libros, 2003.

Ojeda, Claudia. "Diana Bellessi, entre la poesía y la mochila". Tiempo Argentino 2 (1985): 4, Disponible en: www.vendavalsur.com.ar (15/02/2012).

Ricœur, Paul. Sí mismo como otro. México: Siglo XXI, 1996.

Vaccarini, Franco y Mariana Docampo. "Jaque a la dama. Entrevista a Diana Bellessi". La guacha. Revista de poesía (2002), Disponible en: www.vendavalsur.com.ar (25/02/2012). 